\title{
Rapid test for the evaluation of the activity of the prodrug hydroxymethylnitrofurazone in the processing of Trypanosoma cruzi messenger RNAs
}

\footnotetext{
C.F. Barbosa ${ }^{1}$,

E.S. Okuda ${ }^{1}$,

M.C. Chung ${ }^{2}$,

E.I. Ferreira ${ }^{3}$ and

R.M.B. Cicarelli ${ }^{1}$
}

\author{
${ }^{1}$ Departamento de Ciências Biológicas, ${ }^{2}$ Departamento de Fármacos e Medicamentos, \\ Faculdade de Ciências Farmacêuticas, Universidade Estadual Paulista, Araraquara, SP, \\ Brasil \\ ${ }^{3}$ Departamento de Farmácia, Faculdade de Ciências Farmacêuticas, \\ Universidade de São Paulo, São Paulo, SP, Brasil
}

\section{Correspondence \\ R.M.B. Cicarelli \\ Faculdade de Ciências Farmacêuticas UNESP \\ Rod. Araraquara-Jaú, km 01 \\ 14801-902 Araraquara, SP \\ Brasil \\ Fax: +55-16-3301-6940 \\ E-mail: cicarell@fffar.unesp.br}

Research supported by FAPESP (Nos. 99/11393-4, 01/01192-3, 03/05791-4, and 04/01630-9) and PADC/FCF-UNESP (Nos. 2002/12-I and 2004/01-I). E.S. Okuda was the recipient of a fellowship from PIBIC/CNPq.

Received February 16, 2006 Accepted October 27, 2006

\begin{abstract}
No fully effective treatment has been developed since the discovery of Chagas' disease by Carlos Chagas in 1909. Since drug-resistant Trypanosoma cruzi strains are occurring and the current therapy is effectiveness in the acute phase but with various adverse side effects, more studies are needed to characterize the susceptibility of $T$. cruzi to new drugs. Many natural and/or synthetic substances showing trypanocidal activity have been used, even though they are not likely to be turned into clinically approved drugs. Originally, drug screening was performed using natural products, with only limited knowledge of the molecular mechanism involved in the development of diseases. Transsplicing, which is unusual RNA processing reaction and occurs in nematodes and trypanosomes, implies the processing of polycistronic transcription units into individual mRNAs; a short transcript spliced leader (SL RNA) is trans-spliced to the acceptor pre-mRNA, giving origin to the mature mRNA. In the present study, permeable cells of $T$. cruzi epimastigote forms (Y, BOL and NCS strains) were treated to evaluate the interference of two drugs (hydroxymethylnitrofurazone NFOH-121 and nitrofurazone) in the trans-splicing reaction using silver-stained PAGE analysis. Both drugs induced a significant reduction in RNA processing at concentrations from 5 to $12.5 \mu \mathrm{M}$. These data agreed with the biological findings, since the number of parasites decreased, especially with NFOH-121. This proposed methodology allows a rapid and cost-effective screening strategy for detecting drug interference in the trans-splicing mechanism of $T$. cruzi.
\end{abstract}

Key words

- Trypanosoma cruzi

- Trans-splicing

- Trypanocidal drugs

- Permeable cells

- RNA processing

- Hydroxymethylnitrofurazone 


\section{Introduction}

American trypanosomiasis (Chagas' disease) is a major health problem in Central and South America. Approximately 2 to 3 million of about 20 million infected people can develop the characteristic clinical symptoms of the chronic stage of Chagas' disease and 45,000 die every year (1).

Trypanosoma cruzi, the etiological agent of Chagas' disease, shows a pathogenicity pattern that may be influenced by the characteristics of both the human host and the lineage of the T. cruzi strain (2). Thus, the course of infection in susceptible vertebrates is influenced not only by factors such as environmental temperature and the age, sex and genetic constitution of the human host, but also by morphological characteristics of the infecting strains, as well as of therapeutic agents. Treatment of infected people in endemic areas has been recommended by the National Health Foundation of Brazil for acute or recent chronic cases as well as for congenital and accidental infections and for children with positive serology. It is also indicated for patients with acquired immunodeficiency syndrome and for those undergoing organ transplantation or receiving immunosuppressive drugs, who are at risk for reactivation of latent infection with $T$. cruzi $(3,4)$. However, successful treatment with currently used drugs (nifurtimox or benznidazole) is limited by the prevalence of $T$. cruzi strains resistant to these chemotherapeutics (5). It has been shown that resistance is correlated with biological characteristics of the parasite due to the occurrence of various sub-populations of the parasite leading to different host tissue's tropism (6).

Current therapy is based on nifurtimox and benznidazole, which are mostly effective in the acute phase of the disease but may cause serious adverse side effects (5). In Brazil, benznidazole is the only drug available on the market because of the claim that Brazilian T. cruzi strains are resistant to nifurtimox. In addition, several investigators have demonstrated that geographic differences might interfere with the efficacy of therapeutic regimens $(5,7)$. It is urgent to find new and more effective drugs in order to treat patients with chronic disease.

Nitrofurazone (NF), a 5-nitro-furfurylidenesemicarbazone, is primarily an active antimicrobial agent against Gram-positive microorganisms but, due to its side effects, it has been used only for tropical infection $(8,9)$. Nevertheless, a trypanocidal activity of that drug was observed by Andrade and Brener (9). Henderson and co-workers (10) found that its effect could be attributed to inhibition of a trypanothione-reductase, a key enzyme in the oxidative metabolism of the parasite. Despite their toxicity, nitroaromatic compounds are generally very active against $T$. cruzi and have been considered to be important targets for molecular modification $(11,12)$.

Hydroxymethylnitrofuran (NFOH-121), an NF prodrug, showed better trypanocidal activity on all the parasitic forms than its parental drug, NF and/or benznidazole (13, 14), and demonstrated lower mutagenic activity (15). These findings suggested that NFOH-121 might be a very promising compound for in vivo toxicological studies, and for studies directed at establishing its mechanism of action (14).

The objective of the present study was to utilize this novel approach with permeable epimastigote cells of different $T$. cruzi strains to screen and investigate the activity of NFOH-121 and NF on mRNA processing. The method of analysis was standardized using silver-stained gels instead of the traditional radiolabeled nucleotide-based analysis in order to obtain a rapid evaluation of drug interference in the mRNA processing of each strain. Moreover, the biological effects of these drugs were studied against the three developmental stages of the T. cruzi $\mathrm{Y}$ strain. The activity of these compounds against different parasite strains leads us to 
propose NFOH-121 as a candidate drug for the treatment of Chagas' disease patients.

\section{Material and Methods}

\section{Culture of Trypanosoma cruzi epimastigotes}

T. cruzi epimastigote forms of the $\mathrm{Y}$, NCS and Bolivia (BOL) strains were maintained in culture at $28^{\circ} \mathrm{C}$ in LIT medium, with passages every 15 days. For the transsplicing reaction with permeable cells, approximately $10^{5}-10^{6}$ parasites were transferred to $50 \mathrm{~mL}$ LIT and incubated for 7 days at $28^{\circ} \mathrm{C}$. The $\mathrm{Y}$ strain was considered to be the standard (16). The BOL strain has being maintained in the laboratory for some years after isolation from triatominae (17). The NCS strain was isolated from a Chagas' disease patient (Buainain A, personal communication). The NCS and BOL strains are classified as T. cruzi II b/e, but the BOL strain showed different growth features in culture.

\section{In vitro biological assays}

The parasites (T. cruzi $\mathrm{Y}$ strain) were maintained in continuous culture in Dulbecco's modified Eagle's medium (DMEM) supplemented with $\mathrm{NaHCO}_{3}(1.2 \mathrm{~g} / \mathrm{L})$, penicillin (500,000 U/L) and streptomycin (100 $\mathrm{mg} / \mathrm{L}$ ), containing $10 \%$ heat-inactivated fetal bovine serum at $37^{\circ} \mathrm{C}$.

The assay was performed in 24-well tissue culture plates with $2 \times 10^{4} / 2 \mathrm{~mL} \mathrm{LLMCK}_{2}$ (cell lineage provided by Adolfo Lutz Institute, São Paulo, SP, Brazil) maintained in DMEM medium (Gibco-BRL, Rockville, MD, USA), supplemented with $2 \mathrm{mM} \mathrm{L-}$ glutamine, $10 \mathrm{mM} \mathrm{NaHCO}_{3}, 100 \mathrm{U} / \mathrm{mL}$ penicillin, $100 \mu \mathrm{g} / \mathrm{mL}$ streptomycin, and $5 \%$ heatinactivated fetal calf serum. The cultures were incubated at $37^{\circ} \mathrm{C}$ in an atmosphere containing $5 \% \mathrm{CO}_{2}$ and $95 \%$ humidity until the occurrence of cell confluence. Drugs (NFOH-121 and NF) were dissolved in
DMSO and water and diluted in medium to the desired concentrations, with the final DMSO concentrations not exceeding $0.1 \%$ $(\mathrm{v} / \mathrm{v})$. Trypomastigotes $\left(1 \times 10^{6} / \mathrm{mL}\right)$ were inoculated $24 \mathrm{~h}$ after the cell layers were seeded. Fresh medium with or without drugs at concentrations of 5 and $10 \mu \mathrm{M}$ was added to the cells every $24 \mathrm{~h}$ during the incubation period. In vitro activity was determined by counting the number of organisms $6,7,8$, 12,14 , and 15 days after infection. The organisms were counted in a Neubauer chamber as trypomastigotes, amastigotes, or epimastigote-like forms. To facilitate evaluation, only the counts for the 8th and 15th days are reported in this paper.

\section{In vitro trans-splicing reaction using Trypanosoma cruzi permeable cells}

The permeable cell reactions were carried out according to Ullu and Tschudi (18) and Ambrosio et al. (19). In the experiments, $1.25 \times 10^{8} T$. cruzi epimastigote forms (Y, NCS and BOL strains) were washed and resuspended in TB (1X) solution $(20 \mathrm{mM}$ KGlu, $3 \mathrm{mM} \mathrm{MgCl} 2,1 \mathrm{mM}$ DTT, $10 \mu \mathrm{g} / \mathrm{mL}$ leupeptin) and treated with $100 \mu \mathrm{g} \mathrm{L}-\alpha-$ lysophosphatidylcholine and palmitoyl (Lysolecithin, Sigma, St. Louis, MO, USA). To initiate the trans-splicing reaction, a solution containing $2 \mathrm{mM}$ ATP, $1 \mathrm{mM}$ GTP, $1 \mathrm{mM}$ CTP, 1 mM UTP (Gibco-BRL), 0.5X TB, $0.6 \mathrm{mg} / \mathrm{mL}$ creatine kinase (Roche, Basel, Switzerland), and $25 \mathrm{mM}$ creatine phosphate (Sigma) was added. The drugs, NFOH121 and NF, were added separately. After incubation at $28^{\circ} \mathrm{C}$ for $20 \mathrm{~min}$, the parasites were immediately lysed with Trizol (Life Technologies, Rockville, MD, USA) and RNA was recovered by extraction with chloroform and precipitation with isopropanol. The RNA was resuspended in $50 \%$ formamide/5X SET solution and electrophoresed on a $10 \%$ polyacrylamide- $7 \mathrm{M}$ urea gel followed by silver staining (30 min, $40 \%$ methanol/10\% acetic acid; 2 x 15 min, $10 \%$ etha- 
Figure 1. Inhibition of Trypanosoma cruzi growth in culture. Tryp = trypomastigotes; Amast $=$ amastigotes; Epi-like = epimastigote-like forms; NF = nitrofurazone; $\mathrm{NFOH}-121=$ hydroxymethylnitrofuran.
Figure 2. RNAs from Trypanosoma cruzi permeable epimastigote cells of the $\mathrm{Y}, \mathrm{NCS}$, and BOL strains. Cells were treated with the hydroxymethylnitrofuran (NFOH-121) and electrophoresed on $10 \%$ polyacrylamide-7 $\mathrm{M}$ urea gel. $A$, Control without NFOH-121; $B, 2 \mu \mathrm{M}$ NFOH-121; $C, 5 \mu \mathrm{M}$ NFOH-121; $D, 12.5 \mu \mathrm{M}$ $\mathrm{NFOH}-121.1$ 1) Unrelated small nuclear RNA; 2) U2; 3) U1; 4) U4; 5) U5; 6) U6 small nuclear RNAs. Molecular weights in base pairs are given on the left. Silver-stained gel.
Figure 3. RNAs from Trypanosoma cruzi permeable epimastigote cells of the $Y$ strain. Cells were treated with hydroxymethylnitrofuran (NFOH-121) and nitrofuran (NF) and electrophoresed on $10 \%$ polyacrylamide- 7 $\mathrm{M}$ urea gel. $A$, Control without drugs; $B, 2 \mu \mathrm{M} \mathrm{NF}$; $C, 2 \mu \mathrm{M}$ $\mathrm{NFOH}-121 ; D, 12.5 \mu \mathrm{M} \mathrm{NF}$; , $12.5 \mu \mathrm{M} \mathrm{NFOH}-121$. 1) U2; 2) U1; 3) U4; 4) U5; 5) U6 small nuclear RNAs; 6) unrelated small nuclear RNA. Molecular weights in base pairs are given on the left. Silver-stained gel.
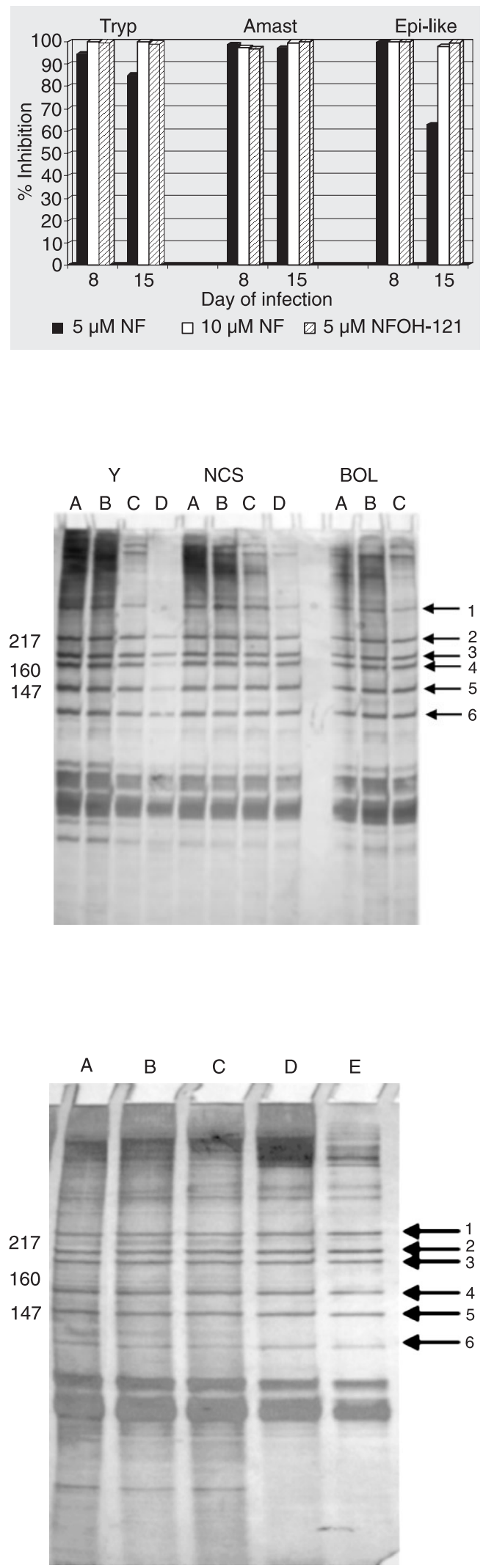

nol $/ 5 \%$ acetic acid; 5 min, deionized water; $20 \mathrm{~min}, 12 \mathrm{mM} \mathrm{AgNO}$; $1 \mathrm{~min}$, deionized water; $0.28 \mathrm{M} \mathrm{Na}_{2} \mathrm{CO}_{3}+0.0185 \%$ formaldehyde until bands became visible).

\section{Quantitation of RNA using Multi Analyst software}

After gel staining, the bands were detected with Fluor-S Image software (BioRad, Hercules, CA, USA) and absorbance was quantified using the Multi Analyst software (BioRad). The values were compared to those obtained with controls without drugs and the percentages of each RNA were calculated.

\section{Results}

The biological tests on cell cultures showed that NFOH-121 was more effective than NF on the trypomastigotes, amastigotes and epimastigote-like forms of T. cruzi. These results, shown in Figure 1, demonstrate that the activity of $5 \mu \mathrm{M}$ NFOH-121 was as effective as double the concentration of the parental drug NF $(10 \mu \mathrm{M})$ for all parasite stages $(\mathrm{P}$ $<0.05)$ and NFOH-121 $(5 \mu \mathrm{M})$ was even more effective after 15 days of treatment (data not shown).

The prodrug NFOH-121 itself reduced the intensities of the small nuclear (snRNA) bands (Figure 2, band 4: U4 snRNA; Figure 3, bands 1-3 and 6: U2, U1, U4 snRNAs and unrelated U snRNA, respectively) at concentrations between 5 and $12.5 \mu \mathrm{M}$. Figure 2 shows these results for the three T. cruzi strains (Y, NCS and BOL). All six RNA bands analyzed in the gel decreased when higher concentrations of NFOH-121 were used, suggesting that the drug did affect RNA processing mainly in the $\mathrm{Y}$ and NCS parasite strains. However, the drug showed no effect on the BOL strain (a higher concentration of the bands compared to the control). Figure 4 presents the absorbance readings of each band.

The activity of NFOH-121 compared with 
the parental drug NF was evaluated either by direct biological activity on the parasites (Figure 1) or by reducing RNA processing (Figures 2 through 5), showing that NFOH121 drug's activity is dose-dependent. The RNA bands were quantified by absorbance (Figures 4 and 5), which confirmed the variation of RNA concentrations.

Both compounds (NF and NFOH-121) were also tested only on Y strain permeable cells using the same concentrations. The results are presented in Figures 3 and 5. The activity of NFOH-121 was higher than that of $\mathrm{NF}$ at $12.5 \mu \mathrm{M}$, supporting the in vitro findings.

\section{Discussion}

The study of new trypanocidal drugs involves specific objectives related to the structure and metabolism of $T$. cruzi, which should be first studied in in vitro experiments (3).

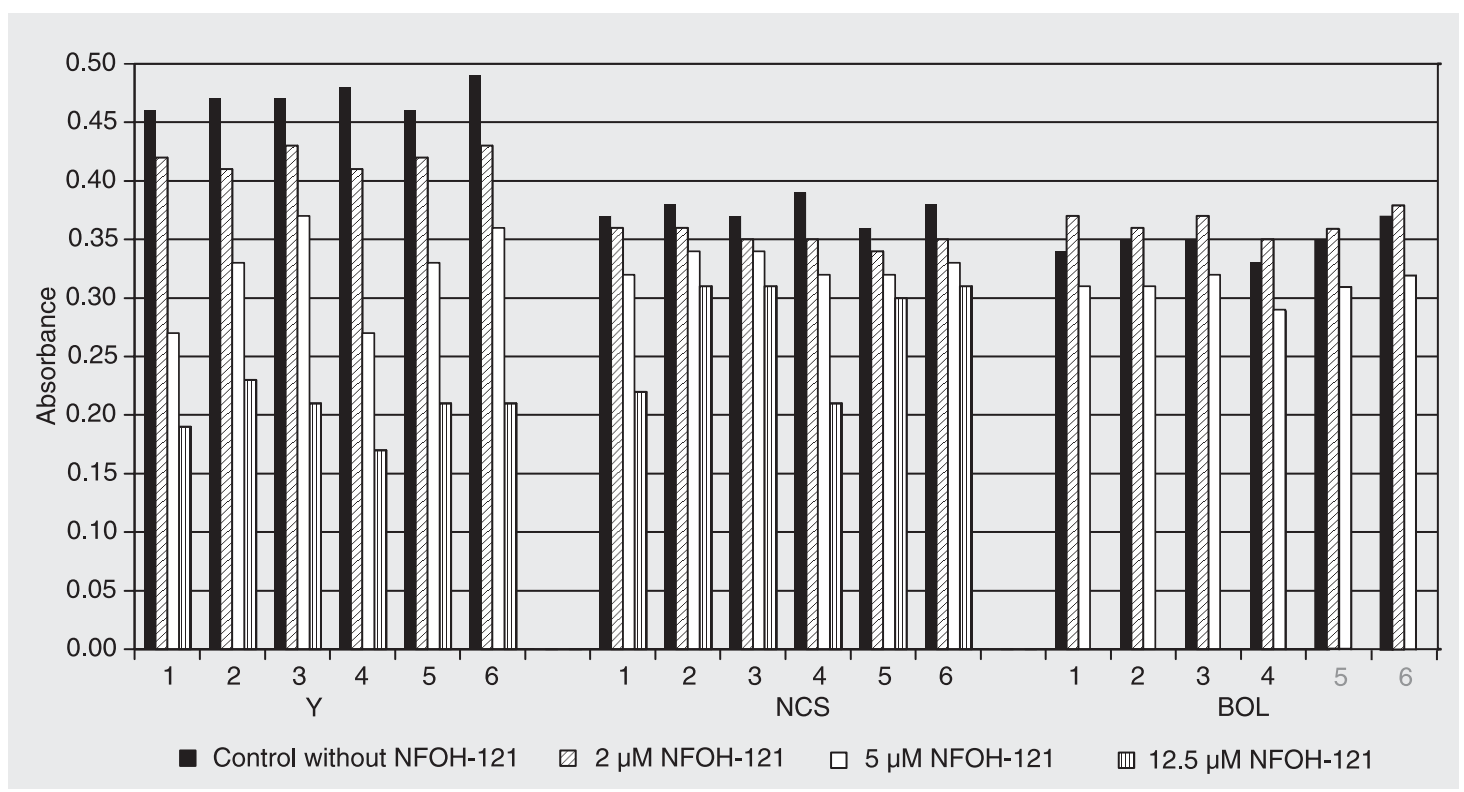

Figure 4. Absorbance values of the bands obtained in Figure 2. Y, NCS and BOL = Trypanosoma cruzi strains; NFOH-121= hydroxymethylnitrofuran.

Figure 5. Absorbance values of the bands obtained in Figure 3. $\mathrm{NF}=$ nitrofurazone; NFOH-121 = hydroxymethylnitrofuran.

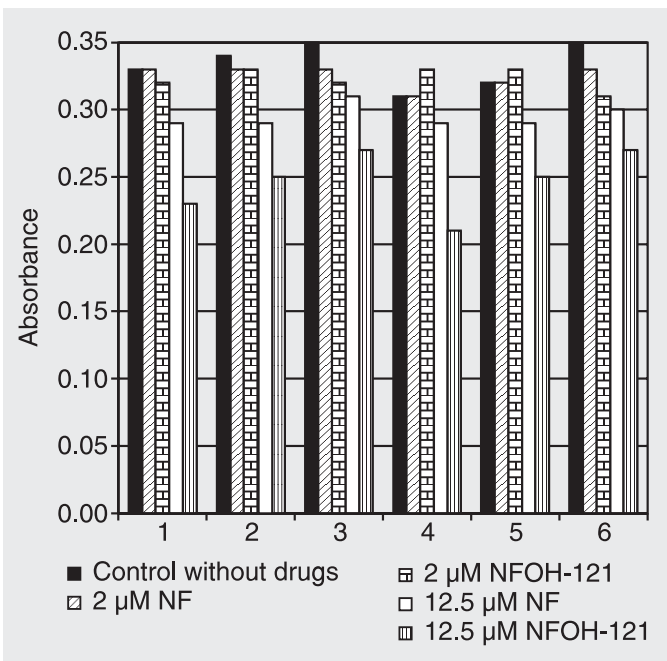


Three $T$. cruzi strains were used in this study. Although all of them belong to parasite lineage II, the BOL strain showed distinct features either under culture or in terms of drug influence. In all experiments, the $\mathrm{Y}$ strain was the most sensitive when compared with the other two strains, NCS and BOL. However, the BOL strain showed the same RNA band pattern even though higher drug concentrations $(12.5 \mu \mathrm{M})$ were used (data not shown). These data also demonstrate that both strains (Y and NCS) were more susceptible to the effect of the drugs, reinforcing the idea that trypanocidal drugs should be tested on different strains, since the strains may behave differently when challenged.

When $T$. cruzi cells are treated with lysolecithin, the parasites become permeable to small molecules (18). Trans-splicing participates in the processing of polycistronic transcription units into individual mRNAs in which a short transcript spliced leader (SL RNA) is trans-spliced to the acceptor premRNA, giving origin to the mature mRNA. We showed that NFOH-121 affected the RNA processing and the trans-splicing reaction, even though at lower intensity (19).

The decrease in the concentration of the small RNAs suggests that the drug interferes with RNA processing. However, the results obtained thus far show that this interference still promotes the trans-splicing reaction in the cells but at a lower rate than observed in the control, indicating that the drug activity did not completely abolish the trans-splicing reaction (19).

In the experiments in which the NF and NFOH-121 activities were compared under the same conditions and at the same concentrations, the higher solubility of NFOH-121 might have been decisive regarding the penetration and toxicity enhancement in all cells tested. Consequently, the higher activity of NFOH-121 than NF also suggests that the effectiveness of the drug can be improved after transformation into the hydroxymethyl derivative. Thus, NFOH-121 activity on the permeable cells was more intense at $12.5 \mu \mathrm{M}$, in agreement with the in vitro biological data.

Because 20 min of incubation of the drug with the permeable cells was probably insufficient to transform all the NFOH-121 molecules, the drug might have interfered mainly with the steps of RNA transcription, promoting a reduction of RNA bands and suggesting that NFOH-121 may be not only a prodrug, but mainly a new agent with trypanocidal activity. These results are compatible with those reported by Ambrosio et al. (19) and in addition suggest that somehow trans-splicing can also be affected in these parasites, since some RNA bands in the gels are related to the small nuclear RNAs involved in this mechanism (20).

It should be pointed out that in the present study RNA analysis was standardized using silver-stained polyacrylamide gels instead of radioactive gels, allowing a rapid, easier and less expensive screening of drug interference with the mRNA processing of parasite cells of different strains and/or different drug concentration simultaneously and using the same cell batch. The results indicate that this methodology is helpful to evaluate drug interference with the transcription/ trans-splicing machinery by using the small RNA band pattern.

In addition, these results, taken together, appear to be very relevant for the study of NF/NFOH-121 drug activity in T. cruzi mRNA processing, suggesting that the latter compound is a very good candidate as a novel trypanocidal drug.

\section{Acknowledgments}

The authors gratefully acknowledge Dr. O.H. Thiemann (Departamento de Física e Informática, Grupo de Cristalografia, Instituto de Física, USP, São Carlos, SP, Brazil) and Dr. W. Colli (Departamento de Bioquímica, Instituto de Química, USP, São Paulo, SP, Brazil) for suggestions and discussion of the experiments. 


\section{References}

1. WHO (World Health Organization). Chagas disease eliminationburden and trends. WHO http://www.who.int; 2003.

2. Macedo AM, Machado CR, Oliveira RP, Pena SD. Trypanosoma cruzi: genetic structure of populations and relevance of genetic variability to the pathogenesis of Chagas disease. Mem Inst Oswaldo Cruz 2004; 99: 1-12.

3. Rodriques CJ, de Castro SL. A critical review on Chagas disease chemotherapy. Mem Inst Oswaldo Cruz 2002; 97: 3-24.

4. Vaidian AK, Weiss LM, Tanowitz HB. Chagas' disease and AIDS. Kinetoplastid Biol Dis 2004; 3: 2-7.

5. de Andrade AL, Zicker F, de Oliveira RM, Almeida SS, Luquetti A, Travassos LR, et al. Randomised trial of efficacy of benznidazole in treatment of early Trypanosoma cruzi infection. Lancet 1996; 348: 1407-1413.

6. Andrade LO, Machado CR, Chiari E, Pena SD, Macedo AM. Differential tissue distribution of diverse clones of Trypanosoma cruzi in infected mice. Mol Biochem Parasitol 1999; 100: 163-172.

7. Camandaroba EL, Reis EA, Goncalves MS, Reis MG, Andrade SG. Trypanosoma cruzi: susceptibility to chemotherapy with benznidazole of clones isolated from the highly resistant Colombian strain. Rev Soc Bras Med Trop 2003; 36: 201-209.

8. Murta SM, Gazzinelli RT, Brener Z, Romanha AJ. Molecular characterization of susceptible and naturally resistant strains of Trypanosoma cruzi to benznidazole and nifurtimox. Mol Biochem Parasitol 1998; 93: 203-214.

9. Andrade ZA, Brener Z. Action of nitrofurazone (5-nitro-2-furaldehyde-semicarbazone) on the intracellular forms of Trypanosoma cruzi in experimental Chagas' disease. Rev Inst Med Trop São Paulo 1969; 11: 222-228.

10. Henderson GB, Ulrich $P$, Fairlamb AH, Rosenberg I, Pereira M, Sela $M$, et al. "Subversive" substrates for the enzyme trypanothione disulfide reductase: alternative approach to chemotherapy of
Chagas disease. Proc Natl Acad Sci U S A 1988; 85: 5374-5378.

11. Croft SL, Seifert K, Duchene M. Antiprotozoal activities of phospholipid analogues. Mol Biochem Parasitol 2003; 126: 165-172.

12. Urbina JA, Docampo R. Specific chemotherapy of Chagas disease: controversies and advances. Trends Parasitol 2003; 19: 495-501.

13. Chung MC. Planejamento e síntese de pró-fármacos recíprocos de nitrofural e primaquina potencialmente antichagásicos. [Doctoral thesis]. São Paulo: Faculdade de Ciências Farmacêuticas, USP; 1996.

14. Chung MC, Guido RV, Martinelli TF, Goncalves MF, Polli MC, Botelho $\mathrm{KC}$, et al. Synthesis and in vitro evaluation of potential antichagasic hydroxymethylnitrofurazone ( $\mathrm{NFOH}-121)$ : a new nitrofurazone prodrug. Bioorg Med Chem 2003; 11: 4779-4783.

15. Güido RV, Ferreira EI, Nassute JC, Varanda EA, Chung MC. Diminuição da atividade mutagênica do pró-fármaco NFOH-121 em relação ao nitrofural (nitrofurazona). Rev Ciên Farm 2001; 22: 319333.

16. Silva LH, Nussenzweig V. Sobre uma cepa de Trypanosoma cruzi altamente virulenta para o camundongo branco. Folia Clin Biol 1953; 20: 191-208.

17. Funayama GK, Prado JC Jr. Estudo dos caracteres de uma amostra boliviana de T. cruzi. Rev Soc Bras Med Trop 1974; 8: 75-81.

18. Ullu E, Tschudi C. Permeable trypanosome cells as a model system for transcription and trans-splicing. Nucleic Acids Res 1990; 18 : 3319-3326.

19. Ambrosio DL, Barbosa CF, Vianna VF, Cicarelli RM. Trypanosoma cruzi: establishment of permeable cells for RNA processing analysis with drugs. Mem Inst Oswaldo Cruz 2004; 99: 617-620.

20. Hannon GJ, Maroney PA, Nilsen TW. U small nuclear ribonucleoprotein requirements for nematode cis- and trans-splicing in vitro. $J$ Biol Chem 1991; 266: 22792-22795. 